\title{
Can Insurance Help Manage Climate Risk and Food Insecurity? Evidence from the Pastoral Regions of East Africa
}

\author{
Michael R. Carter, Sarah A. Janzen, and Quentin Stoeffler
}

\begin{abstract}
Can insurance cost-effectively mitigate the increasingly deleterious impacts of climate risk on poverty and food insecurity? The theory reviewed in this chapter suggests an affirmative answer if well-designed insurance contracts can be implemented and priced at a reasonable level despite the uncertainties that attend climate change. Evidence from the IBLI index insurance project in the pastoral regions in East Africa suggest that these practical difficulties can be overcome and that insurance can have the impacts that underlay the positive theoretical evaluation. At the same time, continuing analysis of the IBLI experience suggests that much remains to be done if quality index insurance contracts are to be scaled up and sustained. We conclude that insurance is not an easy, off-the-shelf solution to the problem of climate risk and food insecurity. Creativity in the technical and institutional design of contracts is still required, as are efforts to forge the more effective publicprivate partnerships needed to price insurance at levels that will allow insurance to fulfill its potential as part of an integrated approach to social protection and food security in an era of climate change.
\end{abstract}

There is ample evidence that climate shocks create and sustain poverty and food insecurity in rural regions of the developing world. There is also ample evidence that climate change is increasing the frequency and severity of climate shocks.

\footnotetext{
M.R. Carter $(\square)$

NBER, Department of Agricultural and Resource Economics and the Giannini Foundation, University of California, Davis, Davis, CA, USA

e-mail: mrcarter@ucdavis.edu

S.A. Janzen

Department of Economics, Montana State University, Bozeman, MT, USA

e-mail: sarah.janzen@montana.edu

Q. Stoeffler

Department of Economics, Istanbul Technical University, Istanbul, Turkey

e-mail: stoeffler@itu.edu.tr 
Together these pieces of evidence in turn provoke the question: Can insurance costeffectively mitigate the increasingly deleterious impacts of climate risk on poverty and food insecurity?

Two inter-related claims suggest an affirmative answer to this question:

1. After a shock is realized (ex post), insurance payments should help families maintain their economic assets (physical and human) and their long-term economic viability. In simpler terms, insurance should help families avoid a (potentially inter-generational) poverty trap.

2. Because it increases ex post security, insurance should also have an ex ante effect through increasing the expected level and certainty of returns to investment. This ex ante 'risk reduction dividend' should allow more families to escape poverty and food insecurity.

Taken together these two arguments suggest that insurance can be a cost-effective instrument to address food insecurity in the face of climate change. As opposed to a policy that simply treats the casualties of climate shocks with, say, food aid transfers, an integrated policy that includes an insurance element may reduce the total required social protection expenditures by addressing the causes, not just the symptoms, of food insecurity. Such an integrated policy cost effective if it allows more more households to maintain and achieve economic viability so that they can take care of their own needs.

The goal of this paper is to interrogate these claims and reflect on obstacles that may limit the efficacy of insurance as an instrument to manage climate risk. To do this, we proceed in several stages. First, in Sect. 1, we use recent theoretical modeling to explore the relative cost effectiveness of insurance as a device to manage the food insecurity induced by climate change. This modeling exercise assumes that:

- A contract can be designed that offers quality protection to inured individuals (i.e., insurance payouts correlate well with household losses) and avoids the problems of moral hazard and adverse selection that can undercut the commercial sustainability of insurance;

- Households understand and trust the insurance and make purchase decisions based on a standard model of economic rationality; and,

- Insurance is commercially priced at the same proportionate levels observed in US crop insurance markets (128\% of the actuarially fair price).

Under these assumptions, we find that while the logic outlined above holds and that integrated social protection, which employs an insurance element, can be a part of smart public policy, especially in the face or climate change. We do find that the relative benefits of an integrated social protection begins to weaken as climate change worsens and insurance itself becomes increasingly expensive.

While the theoretical case for insurance-augmented integrated social protection is clear, can it work in practice-that is, can the three conditions assumed by the theoretical analysis be met in practice? To provide insight into this question, we then turn to a specific case study-livestock insurance in the pastoral regions of northern Kenya and southern Ethiopia-to consider the practical barriers that limit 
the feasibility of insurance as a mechanism to help manage increasing climate risk. Section 2 first shows how satellite-based index insurance has been developed to overcome the most pressing barriers to using insurance for managing risk among low wealth, spatially disperse rural households. Empirical impact evaluations of the Kenya and Ethiopia programs generally support the ex post and the ex ante insurance impacts outlined above.

While this evidence from the pastoral regions of East Africa is promising, even in this area the expansion and sustainability of the insurance contract remains fundamentally challenged by a number of issues, including contract quality, demand and pricing. After putting forward a framework for thinking about the factors that limit the quality of index insurance, Sect. 3 reviews new evidence on the quality of the East African insurance contracts and considers possible future steps for improving their quality. Section 4 then summarizes our findings concerning whether insurance can in practice play a useful role in managing climate risk and food insecurity.

\section{The Logic of Insurance as a Device to Mitigate the Impacts of Climate Change on Food Insecurity}

In an earlier paper, Ikegami et al. (forthcoming) identify what might be termed a social protection paradox. They compare two social protection scenarios.

In the first scenario, which mimics the targeting of conventional social protection programs, a fixed government budget is used to bring all poor households up to the poverty line, or as close to the poverty line as the budget permits. This conventional scenario is purely progressive in the sense that larger transfers go to poorer households. In contrast, a second scenario considered by these authors-which they term a triage policy-is not purely progressive. Instead, the fixed government budget is first allocated to the vulnerable non-poor to keep them from falling below a critical asset threshold, thereby stemming their descent into long-term poverty. These transfers to the vulnerable non-poor are contingent transfers that are only made if an unfavorable shock occurs and threatens the vulnerable with economic collapse. After the contingent needs of the vulnerable are met through these transfers, any remaining budget is then allocated progressively to the poor, again moving all poor households as close to the poverty line as possible.

To compare the effectiveness of these two social protection schemes in managing poverty, Ikegami et al. forthcoming employ a dynamic simulation model, similar to the model developed below. In their model, shocks are realized and individuals optimally choose current consumption and the amount of assets to carry forward to generate future income. Based on household asset and consumption levels, an omniscient government then allocates its budget in accordance with its social protection policy regime. Results are derived for both the standard and the triage regimes. Ikegami et al. forthcoming find that while the extent and depth of poverty are lower 
in the short term under the conventional needs-based approach, those results are reversed in the medium and long terms. In other words, the poor are paradoxically better off in the medium term despite less social assistance being allocated to them and more social assistance targeted to vulnerable but non-poor households.

The reason behind this paradoxical reversal is that when aid is concentrated solely on the neediest and not the vulnerable non-poor, then the number of aideligible poor people slowly swells over time, diluting the resources available for each poor individual. In contrast, transfers to the vulnerable both prevent them from falling below the threshold (and becoming poor) and allow them to successfully build up assets and eventually move away from the threshold and the vulnerability that it implies. Over time, under the triage policy an increasingly large share of the social protection resources become allocable to the poor whose ranks have not grown. We might anticipate that this social protection paradox revealed by Ikegami et al. forthcoming will only become larger in the face of climate change.

Building on this work, Janzen et al. (2015) ask whether or not the contingent transfers envisioned in the Ikegami et al. forthcoming triage policy can be implemented via an insurance contract. Implementing these transfers as an insurance contract would have two advantages. First, it may be able to rely on self-selection, obviating the need for the government to monitor needs and issue payments. ${ }^{1}$ Second, having an insurance contract available could also offer a benefit to nonvulnerable households, including poorer households. To the extent that these latter households pay a portion of the insurance cost, they would be provisioning a portion of their own social protection.

While this logic may seem compelling, prior theoretical studies have suggested that insurance could actually increase the likelihood of collapse by vulnerable house- holds. ${ }^{2}$ However, these other studies ask what happens if vulnerable households are forced to purchase insurance. In contrast to these other theoretical analyses, Janzen et al. (2015) allow individuals to optimally decide and how much insurance to purchase. This difference is subtle but important as Janzen et al. (2015) find that the most vulnerable households optimally purchase only minimal insurance unless it is subsidized. These same households quickly switch to full insurance as soon as they successfully accumulate a small amount of additional productive assets.

Using their model, Janzen et al. (2015) go on to show that the discounted present value of a hybrid policy (which subsidizes insurance and makes cash transfers to close the poverty gap for all poor households) is less than the cost of a conventional transfer program that simply closes the poverty gap for all poor households. After briefly reviewing the Janzen et al. (2015) model, this section then extends their analysis to consider the relative cost effectiveness of an insurance-based hybrid social protection scheme in the face of different climate change scenarios.

\footnotetext{
${ }^{1}$ The Ikegami et al. (forthcoming) policy assumes an omniscient government that can observe shocks and issue precisely the transfer required to protect vulnerable households from slipping into a poverty trap.

${ }^{2}$ See Chantarat et al. (2010) and Kovacevic and Pflug (2011).
} 


\subsection{Theoretical Model of the Ex Post and Ex Ante Impacts of Insurance on Poverty}

Janzen et al. (2015) analyze the following dynamic model of a house- hold optimally allocating its resources across consumption, accumulation of assets that generate income through a risky production process, and purchase of an insurance contract that protects the household against asset losses:

$$
\max _{c_{t}, 0 \leq I_{t} \leq A_{t}} \mathrm{E}_{\theta, \varepsilon} \sum_{t=0}^{\infty} u\left(c_{t}\right)
$$

subject to :

$$
\begin{aligned}
& c_{t}+p I_{t} \leq A_{t}+f\left(A_{t}\right) \\
& f\left(A_{t}\right)=\max \left[F^{H}\left(A_{t}\right), F^{L}\left(A_{t}\right)\right. \\
& A_{t+1}=\left(A_{t}+f\left(A_{t}\right)-c_{t}\right)\left(1-\theta_{t-1}-\varepsilon_{t+1}\right)+\left(\delta\left(\theta_{t+1}\right)-p\right) I_{t} \\
& \delta\left(\theta_{t+1}\right)=\max \left(\left(\theta_{t+1}-s\right), 0\right) \\
& A_{t} \geq 0
\end{aligned}
$$

The first constraint restricts current spending (consumption plus insurance purchases) to cash on hand (current assets plus income). As shown in the second constraint, the model assumes that assets are productive $\left(f\left(A_{t}\right)\right)$ and that the households have access to both a high and low production technology, $\mathrm{F}^{\mathrm{H}}\left(A_{t}\right)$ and $\mathrm{F}^{\mathrm{L}}\left(A_{t}\right)$, respectively. Fixed costs associated with the high technology make it the preferred technology only for households above a minimal asset threshold. As has been demonstrated elsewhere, this non-convexity in the production function can lead to multiple equilibria and a poverty trap. Households with assets above a critical threshold level will strive to reach to a higher, non-poor equilibrium level of asset holdings and consumption. Those who begin with assets below that level (or whom shocks push below that level), will settle down at a lower level of asset holding typified by lower consumption and a poor standard of living.

Assets are subject to stochastic shocks (or depreciation). The random variable, $\theta_{\mathrm{t}+1} \geq 0$ is a covariant shock and $\varepsilon_{\mathrm{t}+1} \geq 0$ is an idiosyncratic shock. ${ }^{3}$ Both shocks are exogenous and realized after decision-making in the current period $(t)$, but before decision-making in the next period $(t+1)$ occurs. While these risks affect all households, they play an especially important role for households in the vicinity of the critical asset threshold. Because a shock can send households in this vicinity into a downward spiral to the low level equilibrium, we will refer to these households as the 'vulnerable.'

A unit of insurance can be purchased at a price $p$ and the insurance payout is based on the realized covariant shock according to the linear indemnity schedule:

\footnotetext{
${ }^{3}$ The distinction between these two stochastic elements will become important later when we consider feasible insurance mechanisms in the next section.
} 


$$
\left.\delta\left(\theta_{t}\right)=\max \left(\left(\theta_{t}\right)-s\right), 0\right),
$$

where $s$ is the contractually determined depreciation rate above which insurance indemnity payments begin. Note that this insurance mechanism is akin to an index insurance mechanism as it only pays based on common or covariant shocks and does not provide protection against idiosyncratic shocks.

The third constraint is the equation of motion for asset dynamics: period $t$ cash on hand that is not consumed by the household or destroyed by nature is carried forward as assets in period $t+1$. Finally, the non-negativity restriction on assets reflects the model's assumption that households cannot borrow. This assumption implies that consumption cannot be greater than current production and assets, but it does not preclude saving for the future.

Figure 1 presents some of the key results from the Janzen et al. (2015) analysis of this dynamic model. The horizontal axis represents time periods ("years") in the dynamic model. The vertical axis measures the headcount poverty rate for a stylized economy under three scenarios: An autarky scenario in which no insurance contracts are made available; A market-based insurance scenario in which insurance costs $120 \%$ of its actuarially fair price; and, A targeted insurance subsidy scenario in which the government pays half of the commercial insurance premium for all households that hold assets less than the level required to generate an average income equal to $150 \%$ of the poverty line. In all cases, the simulation assumes that households behave optimally based on the price of insurance and the dynamic choice problem displayed above.

As can be seen from Fig. 1, under the autarchy scenario with no insurance, headcount poverty steadily increases over time by about $25 \%$, rising from $40 \%$ to $50 \%$ of the population. Under the targeted insurance subsidy scheme, there is an initial uptick in consumption poverty from $40 \%$ to $50 \%$. This initial rise reflects the decision of vulnerable or near poor households to consume at levels below the poverty line in order to invest and (or) purchase insurance. However, over the longer-term, when insurance is partially subsidized for less well-off households, consumption poverty eventually falls to about $15 \%$ of the population, as opposed to the $50 \%$ level that occurs when there is no insurance market. This long-term drop in consumption poverty when insurance is available and subsidized reflects the fact that a significant fraction of the vulnerable ultimately escape the poverty trap. In contrast, without insurance, more of these vulnerable households fail and swell the ranks of the income poor. When an asset insurance market simply exists, but contracts are not subsidized, the impacts on poverty dynamics are qualitatively similar to the impacts of subsidized insurance, but quantitatively, the impacts are roughly two-thirds the magnitude of the impacts of subsidized insurance. This smaller impact occurs because the risk reduction dividend effects are smaller when insurance is more costly. ${ }^{4}$

\footnotetext{
${ }^{4}$ Janzen et al. (2015) discuss in detail how the price of insurance changes optimal insurance purchase and asset investment decisions.
} 


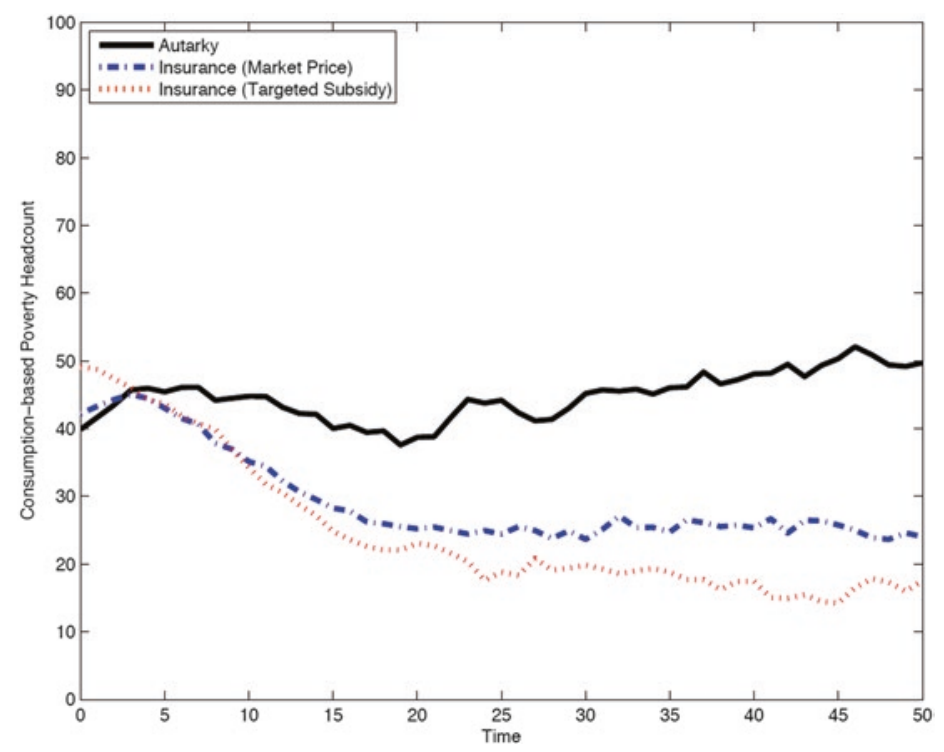

Fig. 1 Consumption poverty headcount (Source: Janzen et al. (2015))

To gauge the cost-effectiveness of insurance subsidies from a public finance perspective, Janzen et al. (2015) sum the cost of all required cash transfer payments and add to that amount the cost of targeted insurance subsidies. Their analysis reveals an intertemporal tradeoff. The cost of transfers cum insurance subsidies is initially quite high, but over time total social protection costs are higher under the scheme that only provides cash transfers. Achieving the lower long-term poverty measures afforded by insurance subsidies costs more money in the short- term, but leads to substantial long term savings. Using a $5 \%$ discount rate the net present value of the two public expenditure streams over the 50 year time horizon of the simulation are $16 \%$ lower under the targeted subsidy scheme. Note of course that the public expenditures are only a portion of the full cost of social protection under the insurance scheme as individuals are in some sense privately provisioning a portion of the cost of their own "social" protection.

\subsection{Analysis of Climate Change Scenarios}

The analysis reported in Janzen et al. (2015) assumes a baseline risk scenario that is roughly calibrated to the climate conditions of the pastoral regions of East Africa circa the year 2000. In order to explore the effectiveness of the insurance cum social protection scenario explored by Janzen et al. (2015), we took their model and slowly increased the frequency and severity of the covariant shocks. Figure 2a shows the 
(a) Baseline Scenario

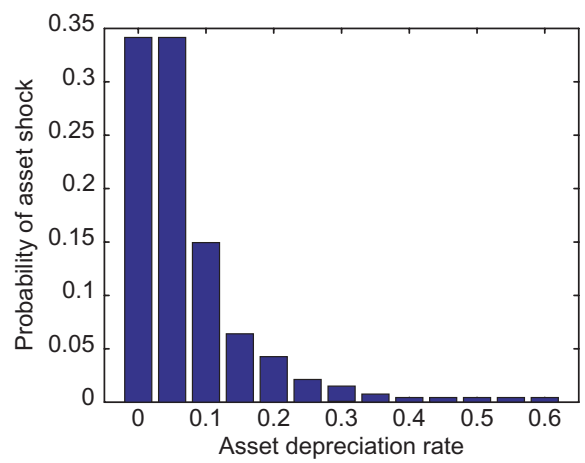

(b) Year 50 Scenario

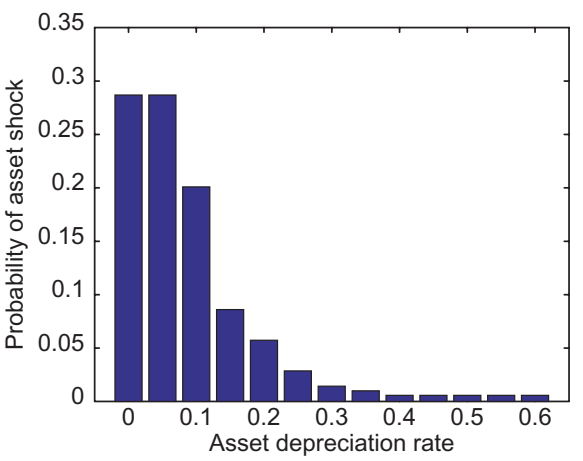

Fig. 2 Climate change scenarios

baseline scenario on which these results are based. ${ }^{5}$ Over a 50 year simulation scenario, we then allowed the climate to worsen every decade. Figure 2 shows the distribution of shocks assumed to exist in the final decade of the simulation. The analysis assumes that individuals are fully informed about the less favorable climate and adjust their behavior accordingly. The cost of insurance is also re-priced with every shift in climate, raising its costs, and the cost of the associated targeted insurance subsidies.

Figure 3 explores the costs of using subsidized insurance as part of a social protection package that seeks to eliminate poverty by transferring to every indigent household the amount of money necessary to lift them to a level of consumption achievable at the poverty line. The vertical axis measures the percentage change in government expenditures relative to the the year-zero transfers that would be required to close the poverty gap for all households under the alternative social protection policies. Results are again shown for three policy scenarios (autarkic risk management; unsubsidized insurance; and, subsidized insurance for poor and vulnerable households). For ease of comparison, we also include the social protection cost trajectories for a given policy both with and without climate change.

As can be seen, as climate change kicks in at year 10 of the simulation, the costs of cash transfers needed to close the poverty gap for all poor households begins to skyrocket above the costs absent climate change. Interestingly, even though insurance becomes increasingly expensive, it manages to hold steady the total cost of social protection (insurance and cash transfers) across the first 3 decades of climate change. This result attains in part because during the first decade of the simulation, many households are able to escape vulnerability and accumulate sufficient assets such that they are no longer eligible for insurance subsidies.

However, when the fourth round of climate change kicks in at year 40 of the simulation, the total costs of social protection begin to accelerate. The hybrid social protection continues to be cost-effective public policy, but as risk rises to an ever higher level, even the hybrid policy begins to loose its effectiveness in absolute terms.

${ }^{5}$ The risk levels at baseline in the simulations that follow are similar, but not directly comparable 


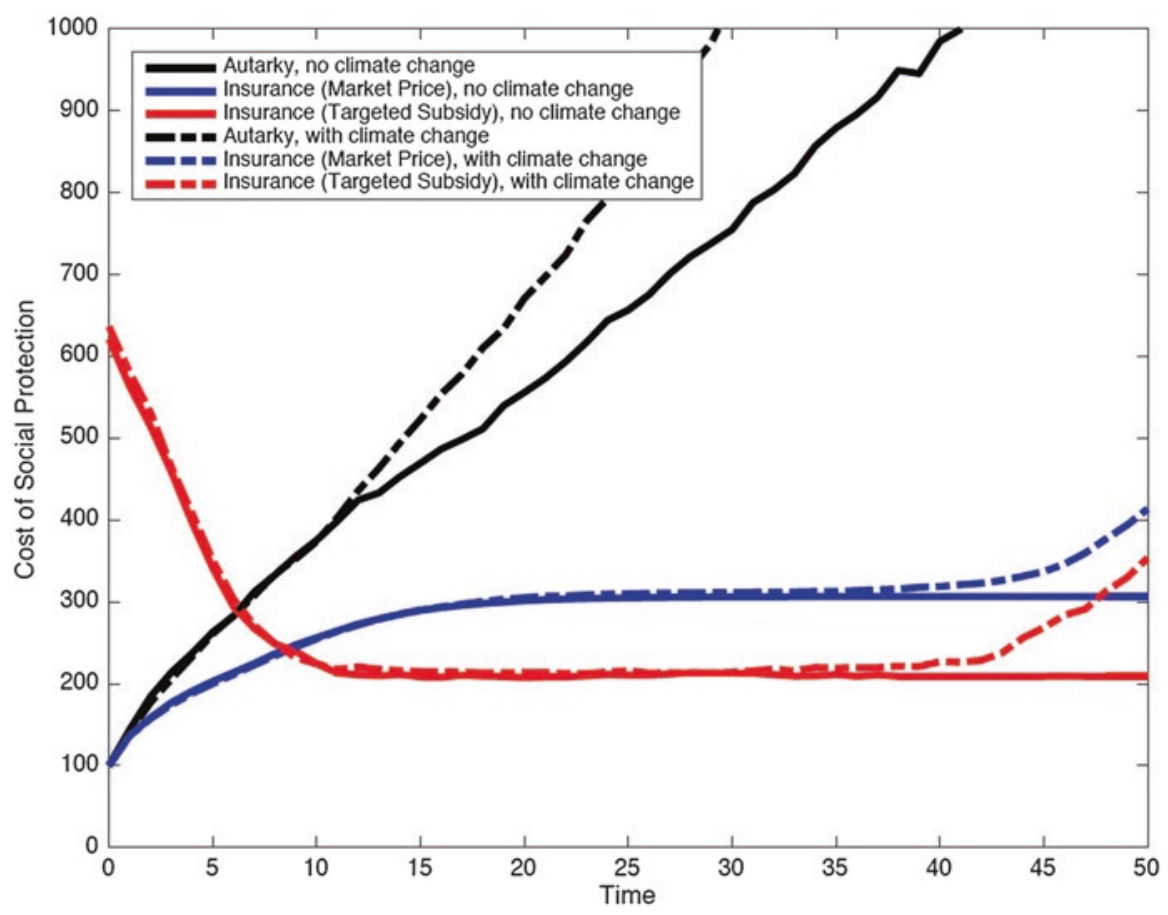

Fig. 3 Cost of social protection

\section{Index Insurance as a Solution: Livestock Insurance in the Pastoral Regions of East Africa}

Section 1 employed abstract modeling techniques to consider the public finance case for insurance as a mechanism to offset the negative impacts of climate change on poverty and food insecurity. While it is relatively easy to implement an insurance policy in a theoretical model, a key question is whether it is possible to implement an insurance scheme in the real world that offers quality insurance protection, while keeping administrative costs, moral hazard and adverse selection in line.

Conventional agricultural insurance, which requires field visits to verify loss claims by individual households, has a dismal record when applied to small-scale rural house- holds, especially those located in isolated areas. In a study of a conventional insurance program established with heavy subsidies for the small-farm sector in Ecuador, Carter et al. (2014) find that the costs associated with a single loss verification visit may exceed $\$ 400$. Given that the total annual premium associated with 
the typical small scale farmer is less than $\$ 100$, it is easy to see why the business case for individual insurance evaporates. Cutting corners on loss verification is an open invitation to morally hazardous behavior. Moreover, given that it is not cost effective to individually rate the loss probabilities for each and every small-scale farmer, conventional insurance is also subject to problems of adverse selection in which those households most likely to experience a loss are also most likely to buy the insurance. As summarized by Hazell and Valdes (1985) and Hazell (2006), the net result of these problems has been loss ratios well in excess of $100 \%$, implying that the insurance cannot be financially sustained.

Against this backdrop, index insurance appears as a promising, cost-effective solution. Under index insurance, loss verification is not required because payouts are based on an index. For agricultural insurance the index might be yields measured directly or predicted by satellite-based biomass growth indicators for an insurance zone. ${ }^{6}$ The index is meant to be highly correlated with, but not identical to, the losses experienced by individual farmers. In principal, index insurance should eliminate problems of high transactions costs, moral hazard and adverse selection. However, its key advantage is also its achilles heel. If the insurance index is only weakly correlated with farmer losses (as Clarke et al. (2012) show in the case of rainfall insurance in India), then index insurance is more similar to a lottery ticket than an insurance contract. Lottery tickets are as likely to pay out when farmers have good crops as when they have bad crops, meaning that lottery ticket 'insurance' is likely to destabilize farmer income by perversely transferring money from bad to good states of the world.

If index insurance is to be part of the solution to helping manage climate risk, then the challenge is clearly to design an insurance index that is sufficiently well correlated with farmer losses such that it offers real ex post protection and thereby incentivizes ex ante investment such that the risk reduction dividend is gained. The remainder of this section focusses on one of the better researched index insurance projects, the IBLI (index-based livestock insurance) program in the semi-arid pastoral zones of northern Kenya an southern Ethiopia.

\subsection{Designing the IBLI Index Insurance Contract}

As detailed by Chantarat et al. (2013), the IBLI project began with the notion that satellite measures of vegetative growth, which had been in use for some time as part of famine early warning systems, might provide a reliable measure of forage availability for pastoral households. This measure was then transformed into an

\footnotetext{
${ }^{6}$ Because the index is the same for all households in the insurance zone, it does not matter in terms of payout probabilities whether high or loss risk producers select into purchasing the insurance, eliminating the adverse selection problem (assuming that the insurance is priced correctly for each zone). Moreover, as long as the zone is large enough, then moral hazard problems also disappear as no single farmer can influence the index by her actions.
} 
index of predicted livestock mortality losses experienced by pastoral households in drought years.

Figure 4 displays "NDVI" maps for the original IBLI insurance zones in the Marsabit District of Northern Kenya. NDVI (or the Normalized Difference Vegetation Index) measures the intensity of light reflected from the earth's surface in different spectral bands. NDVI is essentially a 'greeness' measure that follows a regular cycle as rains come and forage crops grow. The maps displayed in Fig. 4 are based on a pixel size of $8 \mathrm{~km}$ by $8 \mathrm{~km}$-that is, each square of this size receives its own unique NDVI reading on a daily basis as the satellite passes overhead. ${ }^{7}$ The plot on the left shows a year with normal conditions, whereas the plot on the right shows a year where drought pressure was severe and livestock losses were high.

While NDVI can clearly distinguish drought from non-drought years, the insurance quality question swings on how well economic losses experienced by pastoralist households can be explained by the NDVI measure. To answer this question, Chantarat et al. (2013) assembled historical data on livestock losses and estimated a non-linear response function that maps NDVI signals into observed livestock mortality losses. Figure 5 gives a sense of the predictive accuracy of this mapping for one of the insurance zones in Marsabit District. Using out-of-sample prediction tests, Chantarat et al. (2013) report that based on the estimated response function and the historical distribution of NDVI, households would have been correctly indemnified $75 \%$ of the time when they experienced severe mortality losses (those in excess of $30 \%$ ). The level of predictive accuracy falls to $60 \%$ when losses are $30 \%$ or less.

While imperfect, the predictive accuracy of the IBLI mortality was sufficiently high that a pilot project was launched in 2009. ${ }^{8}$ While often hampered by implementation problems, the IBLI contract continues to date. Originally rolled out as a randomized controlled trail, the IBLI case study provides an excellent opportunity to learn, not just if index insurance can be implemented, but if it also delivers the expected ex post and ex ante effects that motivate the use of index insurance as a cost-effective device to help mitigate the costs of climate change. We turn now to consider some of that evidence.

\subsection{Impacts of the IBLI Contract on Ex Post Coping and Ex Ante Investment}

Severe drought in northern Kenya in 2011 resulted in high rates of livestock mortality in the IBLI pilot zone, with mortality estimates ranging from $25 \%$ to $50 \%$. In accordance with the contract, all insured households received indemnity

\footnotetext{
${ }^{7}$ The current version of IBLI operates with much smaller grids based on changes in satellites and satellite technology.

${ }^{8}$ More recent work by Barré et al. (2016) proposes specific quality measures and a safe minimum standard for contract quality.
} 
Normal year (May 2007)

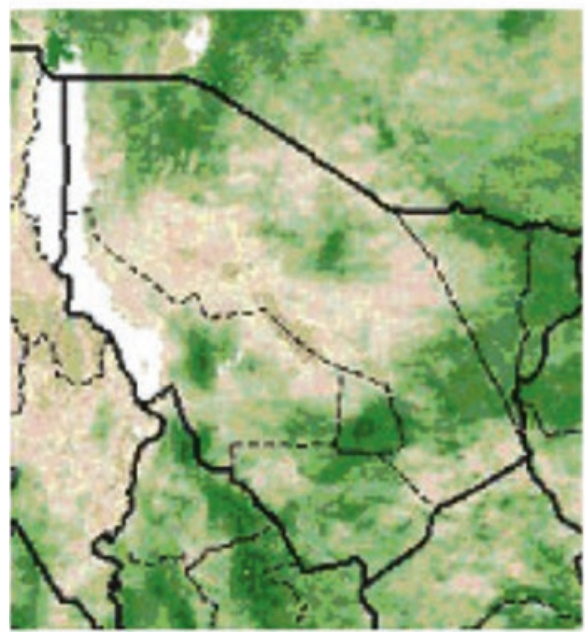

Drought year (May 2009)

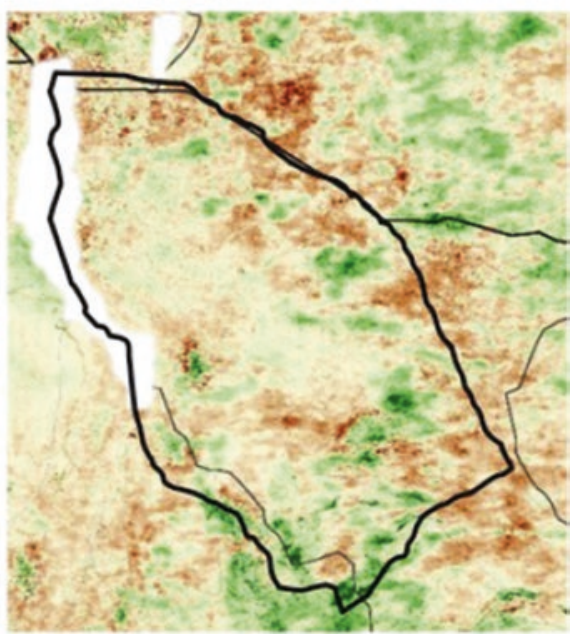

Fig. 4 Satellite-based NDVI measures of forage availability

payments in October 2011. These payments coincided with the round 3 survey of IBLI study households. While the coincidence of the survey and the payments made it impossible to observe the short run impacts of the payments on coping strategies, households were asked what their coping strategies had been the third quarter of 2011 (the period immediately preceding the payouts, but well into the period of drought losses) and what they anticipated their coping strategies would be in the fourth quarter of 2011. Janzen and Carter (2013) use this data to study the impacts of insurance on families' ability to maintain their assets and food security during and after the severe drought. They achieve causal identification of impacts by exploiting randomly distributed inducements for households to actually purchase the insurance.

The first half of Table 1 summarizes the results of the Janzen and Carter (2017) analysis. The table reports the estimated percentage point reduction in the indicated coping strategy caused by insurance. For example, when pooling all households together, insurance causes $25 \%$ point reduction in the probability that the household relies on meal reduction to cope with the drought in the immediate post- payout period.

The first column of the table displays the estimated average impacts of insurance. Looking at the post-payout period, we see that on average insured households reduce anticipated reliance on meal reductions by $25 \%$ points and anticipated reliance on livestock sales by $36 \%$ points. Looking at the quarter 3, immediate prepayout figures, we see-perhaps surprisingly-that insurance reduced by $20 \%$ points households' reliance on meal reduction. This decrease presumably reflects households' anticipation of the impending insurance payments, which allowed them to reduce hoarding of available food and other stocks. 


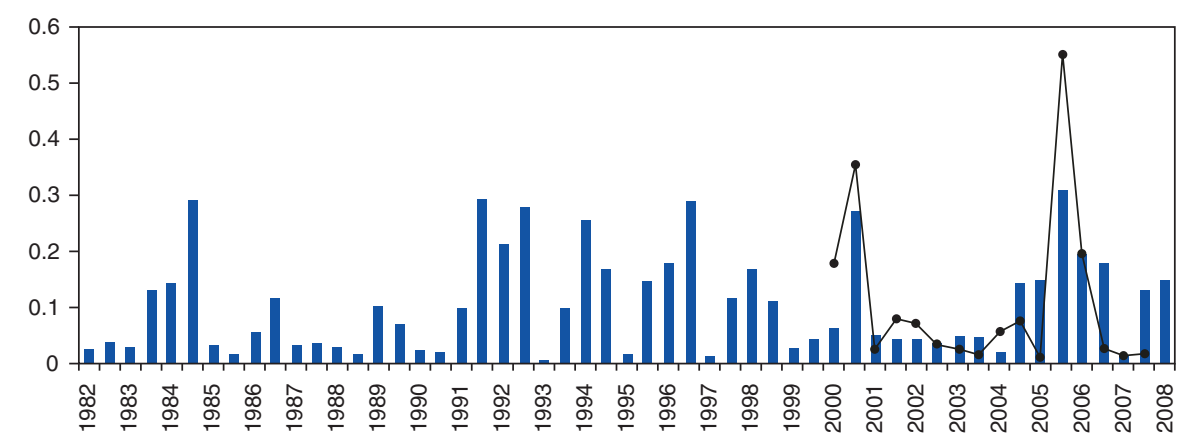

Predicted $\longrightarrow$ Actual

Fig. 5 Predicted versus actual mortality losses

Table 1 Causal Impacts of Insurance.

\begin{tabular}{l|l|l|l}
\hline & All & Poor & Non-poor \\
\hline Ex Ante Risk Management Strategies & \multicolumn{2}{l}{} \\
\hline Reduce Meals & $-20 \%$ points & $-30 \%$ points & - \\
\hline Sell Livestock & - & - & - \\
\hline Ex Post Risk Coping Strategies & $-25 \%$ points & $-43 \%$ points & - \\
\hline Reduce Meals & $-36 \%$ points & - & $64 \%$ points \\
\hline Sell Livestock & \multicolumn{5}{l}{} \\
\hline Overall Welfare & $+3 \%$ & $+1 \%$ & - \\
\hline Income & +1 s.d. & - & - \\
\hline MUAC scores & & - & - \\
\hline Investment & $+72 \%$ & - & \\
\hline Expenditures on Livestock &
\end{tabular}

Sources: Janzen and Carter (2017); Jensen et al. (2014a); Jensen et al. (2016)

While these average effects are impressive, looking beyond the averages tells a richer and perhaps more compelling story. As discussed by Janzen and Carter (2017), poverty trap theory (and other theoretical perspectives) suggest that poorer house- holds will confront shocks by holding onto productive assets and destabilizing consumption. While this 'asset-smoothing' behavior reflects an understandable effort to avoid falling into a long-term poverty trap, its impacts on the next generation's human capital are potentially large. ${ }^{9}$ At the same time, wealthier households would be expected to respond ex post to a shock by selling assets and smoothing consumption.

Motivated by these theoretical propositions, Janzen and Carter (2017) use threshold estimation techniques to test for the presence of a critical asset threshold around

\footnotetext{
${ }^{9}$ See the analysis in Carter and Janzen (2015) for an effort to model these consequences as well as references to other empirical literature that documents this asset smoothing behavior.
} 
which coping behavior switches between asset and consumption smoothing. This estimated threshold is used to distinguish between the poor and non-poor in Table 1. the results are striking. The average post-payout results disguise a strongly heterogenous pattern of insurance impacts. The decrease in meal reductions as a coping strategy is driven almost entirely by poorer households below the threshold, whereas the reduced reliance on livestock sales is driven almost entirely by households above the estimated threshold. These estimates tell an interesting story about the impact of insurance on ex post coping strategies. It appears to equally help both poor and non-poor (or at least less poor) households avoid costly coping strategies with potentially deleterious long-term consequences. But the mechanism through which insurance achieves this end is distinctive across the two sub-populations.

The second half of Table 1 reports the results of two additional impact evaluations that take advantage of rich panel data collected for the evaluation of IBLI. Both studies (Jensen et al. 2014b, 2016) also use randomly distributed premium discount coupons to instrument for IBLI purchases. Jensen et al. (2014b) show that insured households demonstrate improved child health (as measured by MUAC) and increased income per adult equivalent. An examination of production strategies also finds that house- holds with IBLI coverage reduce herd sizes and invest more heavily in health and veterinary services for their remaining herd, which is associated with increased milk productivity (and milk income) within the herd. Without explicitly estimating a threshold (as in Janzen and Carter (2017)), Jensen et al. (2016) also reveal heterogeneous impacts, at least for income: ${ }^{10}$ the impact on income is significant only for the poorest households. These changes signal the kind of ex ante investment impacts discussed in the introduction, complementing the ex post impact findings of of Janzen and Carter (2017).

\section{Limitations to Index Insurance as a Solution for Climate Change and Food Insecurity}

While the economic case for index insurance as a smart response to managing climate risk and food insecurity is well developed, and while the IBLI project itself has shown that workable contracts can be devised that deliver the anticipated ex ante and ex post benefits of insurance, it remains far from clear whether index insurance can be scaled and operate as an essential part of the solution to the problem of climate change and food insecurity. Two of the fundamental challenges that may prevent index insurance from reaching its potential are:

\footnotetext{
${ }^{10}$ Jensen et al. (2014a) find no statistically significant difference in impacts for income, MUAC, or investment in their original analysis. They do find a larger impact in milk productivity among poor households, which may partially explain the heterogenous income results revealed in the latter study.
} 
1. Demand: Similar to other settings, Jensen et al. (2014b) found that poorer households (in this case, smaller herds) are less likely to purchase IBLI coverage, that liquidity plays an important role in the purchase decision, and that demand is price sensitive. In the model presented in Section 1, Janzen et al. (2015) find that the most vulnerable households, despite having the most to gain from insurance, also have a high opportunity cost of insurance that may inhibit demand for an otherwise valuable product.

2. Pricing: A variety of factors have tended to push the price of index insurance contracts in developing country agriculture-including the IBLI project-to levels well in excess of $150 \%$ of the actuarially fair price. ${ }^{11}$ Small project size is clearly a problem (as many insurance companies do not see it worth their while to participate in these markets), as are thin data problems which makes insurers have imprecise estimates of loss probabilities. Carter (2013) suggests that insurance pricing seems to reflect an 'uncertainty loading,' meaning an extra mark-up that charged when data are of mixed quality and loss probabilities uncertain. Solution to these problems may ultimately require a mixed private- public reinsurance model to keep the price of insurance in the range that it is rational to buy it.

While these challenges are clearly important, in the remainder of this section, we focus on a third, equally important challenge-that of providing scalable high quality contracts. While the IBLI contract was designed with much more care and attention to the ability of the index to adequately cover losses (see Section 2 above), even the IBLI contract shows signs of quality slippage as more data and experience become available. This section analyzes these challenges and suggests a way forward to address them and make IBLI an efficient instrument that protects Kenyan herders from the threat represented by climate change.

\subsection{The Quality Challenge to Index Insurance}

Unlike conventional insurance, index insurance includes a remaining uninsured "basis risk": a farmer or herder may encounter losses when the index does not trigger, or that the index may trigger when she does not have any loss. In the model above, this element was captured with the idiosyncratic risk component. Losses triggered in the model by idiosyncratic shocks were not compensated in the model. It is now widely recognized that basis risk may prevent index insurance to achieve its promise of delivering affordable protection to poor households (Miranda and Farrin 2012; Jensen and Barrett 2015). Clarke (2016) shows that because of basis risk, the most risk averse households may not be interested in purchasing index

\footnotetext{
${ }^{11}$ The actuarially fair price of an insurance contract is the price that is just equal to the expected indemnity payments to the farmers. Clearly the price must be marked up in excess of that amount in order to cover administrative costs, cost of capital, etc. However, a price that is, say, $150 \%$ of the actuarially fair price means that the farmer (or whoever is paying the insurance premium) is paying $\$ 1.50$ for every $\$ 1.00$ of protection for the farmers.
} 


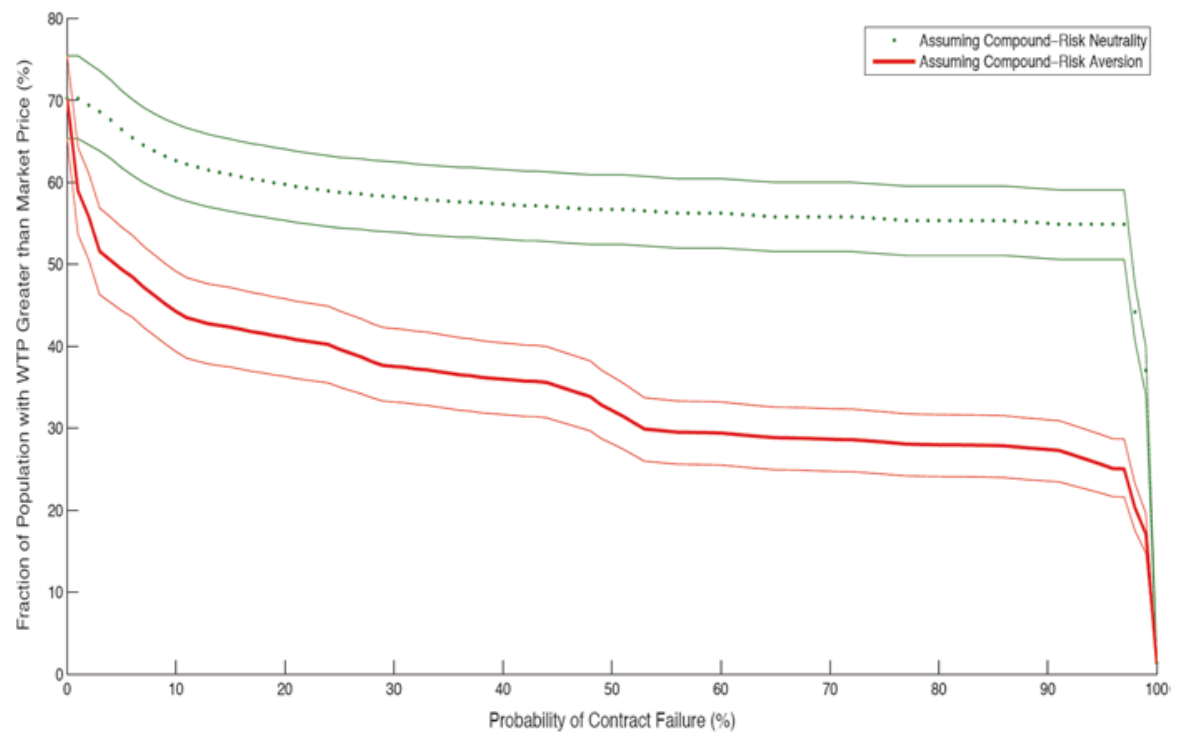

Fig. 6 Impact of basis risk on willingness to pay for index insurance (Source: Elabed and Carter (2015))

insurance products. Indeed, if they have losses, pay a premium, and fail to receive insurance premiums, they end up in a worse situation than without insurance.

Basis risk may be an even bigger problem than work like Clarke (2016) suggests. Elabed and Carter (2015) use a field experiment in Mali to show that behavioral fac- tors related to basis risk further affect insurance demand. Specifically they show that people dislike the uncertainty of insurance payments, which, added to the original uncertainty of shocks, creates a "compound risk aversion" (the aversion to the combination of two uncertain events) among some households. This behavioral reaction generates a drop in insurance demand from $60 \%$ approximately for compound-risk neutral individuals, to only $35 \%$ of the population when compoundrisk aversion is taken into consideration (Fig. 6).

While the necessity to reduce basis risk is now well acknowledged, there exists a debate regarding its exact definition, which harms efforts to increase overall index insurance quality. For example, there is a disagreement on whether basis risk should measure rainfall index correlation with farmers' rainfall shocks (i.e. accuracy of the index as a rainfall predictor) or its accuracy as a predictor of farmers' overall losses overall quality of the protection). Clearly it is the latter that matters from the farmer's perspective and that will influence her insurance purchase decision. A misplaced focus on accuracy of the index as a predictor of, say, rainfall, can lead to inappropriate index insurance products, which trigger payments when rainfalls are low in a given region rather than when farmers have actual losses, as rainfalls in a given region and actual individual losses are, at best, imperfectly correlated. Before analyzing the different sources of low quality of protection, let us step back and examine the objectives of index insurance. 
For households, a good insurance means an insurance which improves their well- being by protecting their consumption and assets (see Barré et al. 2016). In addition, the quality of insurance as a development instrument stems from its ability to foster investments and reallocation of resources- and thus generate higher income- by removing risk. In other words, an insurance product needs to be evaluated based on its efficiency in stabilizing highly volatile income streams for poor farmers or herders. As a consequence, an index insurance product should be carefully analyzed to determine if its expected payments are actually correlated with households' losses, or if the insurance rather acts as a weather derivative-or even worse: as a lottery ticket (Jensen et al. 2014b; Barré et al. 2016). In India, Clarke et al. (2012) have shown that insurance payments actually correlates poorly with farmers' low yield events (Fig. 7).

The inadequacy of indemnity payments, observed in India and other settings, raises the issue of index insurance quality. Several sources of errors lead to low levels of index insurance quality. As shown in Fig. 8, for products which aim at covering all types of shocks, these sources of error relate:

- Design risk occurs when an insurance index is poorly correlated with average losses in the insurance zone covered by the index; and,

- Idiosyncratic risk occurs when the individual's losses differ from the average losses in her insurance zone.

In the theoretical model presented in Section 1, the insurance contract exhibited idiosyncratic, but not design risk.

The red line shows the point estimate for an Epanechnikov kernel with a bandwidth of 0.8 . The green lines show the $95 \%$ confidence intervals for the point esti-

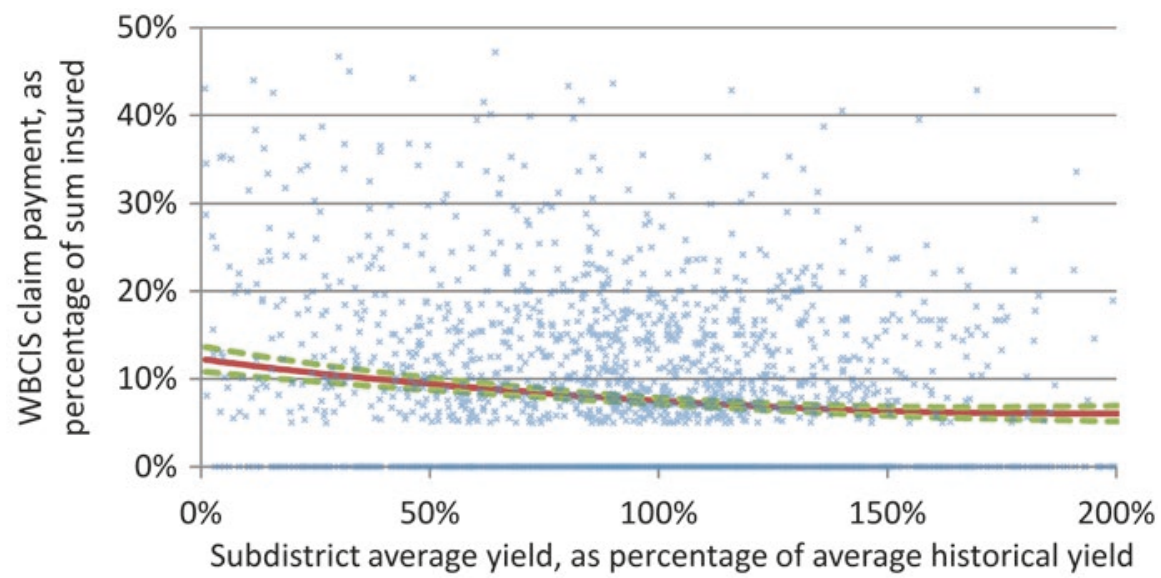

Fig. 7 Relationship between average yields and insurance payments in India (Source: Clarke et al. (2012)) 


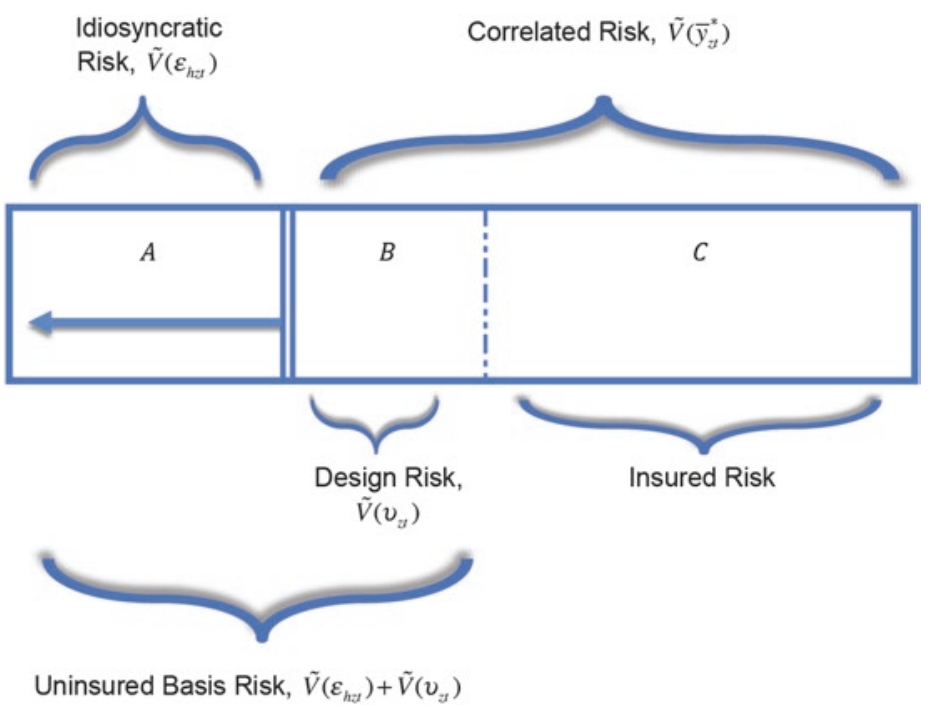

Fig. 8 Insured and uninsured risk under index insurance (Source: Elabed et al. (2013))

mate. The blue dots represent the scatter plot of claim payments for the respective district yield levels.

Design risk emerges from prediction errors embedded in the index. The average loss within a defined geographic zone can be measured by indices based on several methods: crop cutting, satellite information, weather stations, etc. The contract formula then maps the index into payouts (and, implicitly, losses). Both the index and the mapping necessarily include some errors, which can be limited by using good indices and good insurance designs, but will not be eradicated.

However, even if design risk can be eliminated by improving even further the predictive power of the index, there typically remains some uninsured risk at the individual level. Pure idiosyncratic risk may induce households to encounter agricultural losses. For instance, a single farm's crop may suffer damage from idiosyncratic factors such as animal damage. Local communities often have some informal risk management strategies to cope with such type of pure idiosyncratic shocks when other villagers are not affected. Nevertheless, idiosyncratic risk diminishes the overall protection provided to farmers or herders.

The relative magnitude of both design and idiosyncratic risks are both influenced by the nature of the contract and its geographic scale. In terms of Fig. 8, how much risk appears as idiosyncratic and how much appears as correlated depends on the geographic scale of the index. As the geographic zone covered by a single index increases in size, household losses will correlate less well with the insurance index. For example, a weather-based index that covers households within 30 kilometers of the weather station will track outcomes worse than an index that covers households within 1 kilometer of the weather station. Similarly, an area yield index at the level of a state or province will cover individual farmer losses less well than 
an index where yields are measured at the level of each municipality or village. However in practice, reducing the geographic scale of the index too much leads to issues related to moral hazard, i.e. the fear that households may become able to manipulate the index.

Finally, for products which do not aim to cover all types of shocks (such as insurance products based on a rainfall index), an additional source of low quality arise from uncovered covariate risks (e.g., locusts, tsunamis). This type of error is related to the traditional distinction between single-peril and multiple-peril insurance products, but the difference is not as clear in the case of index insurance: satellite-based products such as IBLI, for instance, are supposed to cover all types of shocks related to lack of forage- including increase in livestock diseases- but cannot detect shocks which are not related to the ground vegetation- such as a new epidemic affecting well-fed livestock. These uncovered covariate risks further decrease the quality of the protection offered to poor households. Of course, households may be still interested in affordable index insurance products which only protects from one type of shock (e.g. drought), but the overall protection provided by this type of product has to be carefully analyzed and put in perspective with the price of the product and the probability that a farmer is made worse off with the insurance than without it. ${ }^{12}$

The lack of a strong negative correlation between the insurance indemnities and income shocks due to yield losses will result in a low demand for the insurance product (Clarke 2016; Smith and Watts 2009). Low correlation will not only fail to protect farmers, but eventually seriously damage livelihoods, because poor households pay high premiums to purchase protection, and plan on being protected when making investment decisions. Thus, a detailed analysis of the sources of errors needs to be conducted before implementing an index-based insurance and after its implementation, in order to rule out low quality products and pave the road for future product improvements. While this type of analysis is rarely undertaken in practice, IBLI is one of the most studied index insurance programs, and its quality has been closely scrutinized before and after implementation.

\subsection{IBLI's Quality Effort and Remaining Weaknesses}

IBLI's initial design considered carefully the above quality challenges, employing the available data. Indeed, as summarized in Sect. 2 above, Chantarat et al. (2013) conducted a rigorous ex-ante analysis intended to design the best performing index insurance product in the Kenyan ASALs. However, ex-post analyses have been less optimistic regarding IBLI's index performance in terms of basis risk and contract quality. Jensen et al. (2014a, b) and have investigated IBLI's performance using data collected between 2009 and 2012 (4 years, eight rainy seasons). This dataset was

\footnotetext{
${ }^{12}$ Note that if farmer pays for an insurance that only covers a sub-set of rainfall events, and then she suffers an uncovered pest invasion, she is actually worse off then if she had the invasion but not purchased the insurance. Clarke (2016) discusses these issues in detail.
} 
employed for the impact evaluation of the IBLI pilot and includes detailed information on livestock dynamics, which can be used to assess the actual protection offered to herders over the period.

Jensen et al. (2014a) decomposes basis risk in several ways. First, by considering livestock surviving rates, the authors show that outcomes for insured households do not stochastically dominate outcomes for uninsured households. Actually, as expected, the insurance contract reduces the mean survival rate (taking into account insurance payments) but reduces skewness of the survival rate distribution. Simulations based on a constant relative risk aversion (CRRA) utility function shows that most households are actually better-off with the insurance at the commercial premium rate, but the benefits vary across locations and households.

To unpack these results, the authors decompose uncovered risks between design risk (the IBLI index was a poor predictor of average losses) and idiosyncratic risk (the individual suffered a worse loss than her neighbors on average did). At the aggregate level, design risk is relatively low since IBLI reduces covariate risk by about $62.8 \%$. However, when individual idiosyncratic risk is added, IBLI only covers between $23.3 \%$ and $37.7 \%$ of the total risk. Note that at the individual level, the precision of the index when covariate losses are above the strike point is much higher, between $43.1 \%$ and $78.6 \%$, which is closer to the objective, but still unsatisfying in some districts. Moreover, covering covariate shocks is arguably a first priority, as households may have informal insurance mechanisms when they receive adverse idiosyncratic shocks (Mobarak and Rosenzweig 2012). ${ }^{13}$ Overall, these results call for caution when assessing insurance ex-ante, given that ex-post quality may be lower than expected based on ex-ante, out-of-sample predictions. ${ }^{14}$

An analysis of the consequence of basis risk on insurance demand was further performed by Jensen et al. (2014a). First, basis risk may deter insurance purchase. Second, while index insurance avoids moral hazard issues and individual-level adverse selection, it leaves some room for spatiotemporal adverse selection: households can buy insurance when they anticipate a bad climatic season in a given location, or not buy insurance if they expect a good climatic season in that location. Indeed, households may have an idea of the future season based on their information at the time of the insurance sale, as forage is affected by previous seasons and by the current season early rains. Thus, pastoralists can buy more insurance when they anticipate a bad climatic event- while on the other hand, price tends not to adjust to changing conditions.

\footnotetext{
${ }^{13}$ The complementarity of informal and formal insurance is not straightforward, and depends on the structure of the informal networks and of the index insurance, a point reinforced by Boucher and Delpierre (2014).

${ }^{14}$ The difference between ex-ante and ex-post assessments is striking. Factors explaining this mismatch may include: the use of an out-of-sample prediction which was never used in the design process (thus avoiding overfitting better); the application to a different time period (which was not available at the time of the contract design); the use of more detailed household data; and the computation of mortality rates and basis risk in a different manner.
} 
The analysis shows that price, liquidity and social relationships have a strong impact on index insurance demand. In addition, both basis risk and special adverse selection play a major role. In particular, households in districts with high idiosyncratic risk (which cannot possibly be covered by the index insurance) are much less likely to purchase the IBLI product compared to households living in districts with a higher share of covariate risk. Design risk, on the other hand, plays a much smaller role in diminishing demand by about $1 \%$ only, compared to idiosyncratic risk, which explains about $30 \%$ of the demand. ${ }^{15}$ This conclusion is relatively pessimistic regarding IBLI's potential, as contract design can only address inherent basis risk by lowering the geographic scale of the index. In pastoral regions, where individual households may seasonally migrate across large spaces, there are natural limits to how much a forage index like IBLI can be downscaled.

There are, of course, additional challenges to index insurance quality. ${ }^{16}$ However, these issues of basis risk relate directly to the core economic value of the insurance product. If an index insurance does not pay pastoralists when they have losses, it does not matter how precisely it is priced, how efficiently it is implemented, and whether demand is low or high: households are not protected. ${ }^{17}$ Index insurance products offer imperfect protection by definition, but efforts have to be made to provide the highest quality of protection as possible. Fortunately, there are several improvements that IBLI has realized in the last year or plans on including, which can improve household protection in several manners.

\subsection{The Way Forward}

Since the introduction of IBLI pilot project in 2009, the program has introduced some improvements and is planning further changes based on recent studies which it conducted. As the project has developed, we learned a lot about the strengths and weaknesses of IBLI. New ex-post data have become available at the household

\footnotetext{
${ }^{15}$ Note that design risk is difficult to measure with a short panel and a limited number of observations, as insured catastrophic losses are rare events by definition.

${ }^{16}$ These challenges relate to contract pricing and implementation (Chantarat et al. 2013), and nonprice factors such as trust and liquidity (Jensen et al. 2014b), among others. Climate change also intensifies these challenges, as it creates some short-term uncertainties around future payments (Carter 2013) and may lead to very high premiums if climatic conditions deteriorate in the longrun (Collier et al. 2009; Carter and Janzen 2015).

${ }^{17}$ Of course, for households with full information, demand should be a good indication of the value of an insurance products. However, even for households who understand the product sold, the value of an insurance is difficult to assess ex-ante (Clarke and Wren-Lewis 2013). In addition, households do not always understand very well the insurance product, given the complexity of some index insurance schemes, the low levels of literacy in some contexts, and the poor quality of some marketing/information campains. For that reason, implementation of index insurance projects should focus on the quality of the protection offered rather than on the demand for these products only.
} 
level, as well as longer term satellite information. IBLI has also expanded in scale in four districts in Northern Kenya and one district in neighboring Southern Ethiopia. This combination of factors has brought new opportunities and challenges. While IBLI has already operated some modifications since the studies mentioned above, further studies are planned to help continue improving the product design and the protection it provides to herders.

Notably, the program has evolved from an asset replacement mechanism to an asset protection philosophy. From an economic point of view, it is more efficient to intervene early and protect households' productive assets, rather than compensating them after the received a shock and possibly employed other costly coping strategies (Janzen and Carter 2017). In addition, as the project extended to geographic areas where livestock mortality data were lacking (in particular Southern Ethiopia), IBLI had to rely exclusively on NDVI data. Thus, payments would be triggered when NDVI data indicate a deterioration of the climatic conditions.

This move towards early payments have been accompanied by improvements of the product design. Since 2013, in order to limit spatiotemporal adverse selection, IBLI has started to disaggregate more the index, so that households located in different locations receive appropriate (different) insurance contracts. At this disaggregated scale, a larger share of shocks should be considered as covariate risk by the index, and as such reduce the effect of idiosyncratic risk (Jensen et al. 2014b).

Additional analyses have been conducted to further improve index quality. Vrieling et al. (2014) have investigated the possibility to combine remote sensing indices over longer periods in order to increase the predictive power of IBLI's formula. Based on newly constructed remote sensing from 1981 to 2011, the authors show how combining remote sensing indices allow a higher predictive power at a highly disaggregated level-i.e., there is still scope for reducing the magnitude of idiosyncratic risk by downscaling the insurance index. On the other hand, Klisch et al. (2015) have realized technical improvements in the computation of the vegetation index which can be used to detect droughts. ${ }^{18}$

Finally, Vrieling et al. (2016) have conducted some work on the temporality of the payments. The initial IBLI designed considered fixed dates for beginning and end of season in each district location. However, Vrieling et al. (2016) show that it is possible to use a phenomenological model to describe the temporality of forage development, based on historical NDVI data in each location. This change offers the potential to predict more accurately livestock mortality in each district, but also to provide payments one to three months earlier to pastoralists. These early payments could allow pastoralists to protect their herd by buying forage, water or medicine for instance, and prevent other shocks associated with low levels of forage such as animal diseases.

Additional research is required, however, on the relationship between insurance quality and temporality of payments. If early payments do not compromise the cor-

\footnotetext{
${ }^{18}$ These improvements regard the smoothing and filtering of satellite data, the modelling of uncertainty, the spatial and temporal aggregation of satellite data, and the timing of satellite data acquisition and processing.
} 
relation between insurance payments and household's losses, then they are clearly valuable. However, there may be some trade-offs between early protection and accurate protection. Future work will analyze these trade-offs, as well as measure how the identified improvements in satellite indices computations translate into higher index insurance quality for herders.

\section{Conclusions}

We began this paper with the question:

Can insurance cost-effectively mitigate the increasingly deleterious impacts of climate risk on poverty and food insecurity?

The answer, it seems is both yes and no. Theory suggests that if quality insurance coverage can be delivered and the expected ex post and ex ante impacts take place, then the answer should be yes. Indeed, research on the Index-based Livestock Insurance (IBLI) pilot project in Kenya indicate that these conditions can be met giving further power to the likelihood of a yes answer.

And yet, even within the generally positive environment of the IBLI project, there is ample evidence of the limitations to index insurance. Demand has often been tepid and unstable. Outreach and administration costs have been high. Pricing by a private insurance industry made nervous by climate change has pushed costs up. Finally, the effective quality of the IBLI contact has been scrutinized and found wanting. Efforts to scale the IBLI contract to nearby pastoral regions has proven challenging.

While efforts are underway to respond to these challenges, their breadth and depth make clear that index insurance is not a sliver bullet that can be pulled off the shelf and used to mitigate the food insecurity and other consequences of climate change. Skeptics might suggest that these challenges are insurmountable. Othersand we count ourselves among them-remain undeterred given the evidence that index insurance can be a valuable instrument if these problems can just be solved. Doing so will require continued creativity, piloting and evaluation to see if indeed these not inconsequential challenges can be overcome.

\section{References}

Barré, T. et al. 2016. "Assessing index insurance: conceptual approach and empirical illustration from Burkina Faso." Unpublished.

Barré, T., Q. Stoeffler, and M. Carter. 2016. "Assessing index insurance: conceptual approach and empirical illustration from Burkina Faso." Unpublished.

Barrett, C.B., M.R. Carter, and M. Ikegami. 2013. "Poverty Traps and Social Pro- tection." Unpublished.

Boucher, S., and M. Delpierre. 2014. "The impact of index-based insurance on infor- mal risksharing arrangements." Working paper, CEPS/INSTEAD. 
Carter, M. 2013. "Sharing the Risk and the Uncertainty: Public-Private Reinsurance Partnerships for Viable Agricultural Insurance Markets." I4 Index Insurance Innovation Initiative Brief 1.

Carter, M.R., S. Boucher, and M.J. Castillo. 2014. "Index Insurance: Innovative Financial Technology to Break the Cycle of Risk and Rural Poverty in Ecuador." Working paper, I4, Index Insurance Innovation Initiative.

Carter, M.R., and Janzen, S. 2015. "Social Protection in the Face of Climate Change: Targeting Principles and Financing Mechanisms.” World Bank Policy Research Working Paper WPS7476.

Chantarat, S., A. Mude, C. Barrett, and C. Turvey. 2010. "The Performance of Index Based Livestock Insurance in the Presence of a Poverty Trap." Unpublished.

Chantarat, S., A.G. Mude, C.B. Barrett, and M.R. Carter. 2013. "Designing index- based livestock insurance for managing asset risk in northern Kenya." Journal of Risk and Insurance 80:205-237.

Clarke D. 2016. A theory of rational demand for index insurance. Am Econ J Microecon 8(1):283-306,

Clarke, D., O. Mahul, K.N. Rao, and N. Verma. 2012. "Weather based crop insurance in India." World Bank Policy Research Working Paper, pp.

Collier, B., J. Skees, and B. Barnett. 2009. "Weather index insurance and climate change: opportunities and challenges in lower income countries." The Geneva Papers on Risk and InsuranceIssues and Practice 34:401-424.

Elabed, G., M.F. Bellemare, M.R. Carter, and C. Guirkinger. 2013. "Managing basis risk with multiscale index insurance." Agricultural Economics 44:419-431.

Elabed, G., and M. Carter. 2017. "Ex-ante impacts of agricultural insurance: Evidence from a field experiment in Mali," working paper.

Hazell, P.B.R. 2006. "The appropriate role of agricultureal insurance in developing countries." Journal of International Development 4:567-581.

Hazell, P.B.R., and A. Valdes. 1985. Crop insurance for agricultural development: Issues and experiences,. Baltimore, Maryland, USA: John Hopkins University Press, International Food Policy Research Institute, Washington, DC USA.

Ikegami, M., Carter, M.R., Barrett, C.B. and Janzen, S. (forthcoming). "Poverty Traps and the Social Protection Paradox," in C.B. Barrett, M.R. Carter and J. Chavas The Economics of Asset Accumulation and Poverty Traps (Chicago: University of Chicago Press).

Janzen, S.A., and Cartern, M.R.. 2017. "After the drought: The impact of microinsur- ance on consumption smoothing and asset protection.” NBER Working Paper No. 19702.

Janzen, S.A., M.R. Carter, and M. Ikegami. 2015. "Valuing Asset Insurance in the Presence of Poverty Traps," working paper.

Jensen, N., M. Ikegami, and A. Mude. 2016. "Integrating social protection strategies for improved impact: A comparative evaluation of cash transfers and index insurance in Kenya." Unpublished.

Jensen, N.D., and C.B. Barrett. 2015. "Agricultural Index Insurance for Sub-Saharan African Development.", pp. .

Jensen, N.D., C.B. Barrett, and A. Mude. 2014. "Index Insurance and Cash Transfers: A Comparative Analysis from Northern Kenya." Available at SSRN 2547660.

Jensen, N.D., A. Mude, and C.B. Barrett. 2014. "How basis risk and spatiotemporal adverse selection influence demand for index insurance: Evidence from northern Kenya." Available at SSRN 2475187.

Klisch, A., C. Atzberger, and L. Luminari. 2015. "Satellite-based drought monitoring in Kenya in an operational setting." The International Archives of Photogrammetry, Remote Sensing and Spatial Information Sciences 40:433.

Kovacevic, R., and G.C. Pflug. 2011. "Does Insurance Help to Escape the Poverty Trap? A Ruin Theoretic Approach." The Journal of Risk and Insurance 78:1003-1028.

Miranda, M.J., and K. Farrin. 2012. "Index insurance for developing countries." Applied Economic Perspectives and Policy 34:391-427.

Mobarak, A.M., and M.R. Rosenzweig. 2012. "Selling formal insurance to the informally insured," working paper. 
Smith, V., and M. Watts. 2009. "Index based agricultural insurance in developing countries: Feasibility, scalability and sustainability."

Vrieling, A., M. Meroni, A.G. Mude, S. Chantarat, C.C. Ummenhofer, and K.C. de Bie. 2016. "Early assessment of seasonal forage availability for mitigating the impact of drought on East African pastoralists." Remote Sensing of Environment 174:44-55.

Vrieling, A., M. Meroni, A. Shee, A.G. Mude, J. Woodard, C.K. de Bie, and F. Rem- bold. 2014. "Historical extension of operational NDVI products for livestock insur- ance in Kenya." International Journal of Applied Earth Observation and Geoin- formation 28:238-251.

Open Access This chapter is distributed under the terms of the Creative Commons AttributionNonCommercial-ShareAlike 3.0 IGO license (https://creativecommons.org/licenses/by-nc-sa/3.0/ igo/), which permits any noncommercial use, duplication, adaptation, distribution, and reproduction in any medium or format, as long as you give appropriate credit to the Food and Agriculture Organization of the United Nations (FAO), provide a link to the Creative Commons license and indicate if changes were made. If you remix, transform, or build upon this book or a part thereof, you must distribute your contributions under the same license as the original. Any dispute related to the use of the works of the FAO that cannot be settled amicably shall be submitted to arbitration pursuant to the UNCITRAL rules. The use of the FAO's name for any purpose other than for attribution, and the use of the FAO's logo, shall be subject to a separate written license agreement between the FAO and the user and is not authorized as part of this CC-IGO license. Note that the link provided above includes additional terms and conditions of the license.

The images or other third party material in this chapter are included in the chapter's Creative Commons license, unless indicated otherwise in a credit line to the material. If material is not included in the chapter's Creative Commons license and your intended use is not permitted by statutory regulation or exceeds the permitted use, you will need to obtain permission directly from the copyright holder.

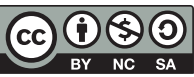

